\title{
A PRESENÇA DA CULTURA INFORMÁTICA NAS ESCOLAS
}

\section{THE PRESENCE OF CULTURE COMPUTERS IN SCHOOLS}

\author{
Adão Caron Cambraia*
}

\begin{abstract}
RESUMO
Esta investigação é sobre como a cultura informática se constitui no âmbito das práticas pedagógicas da escola. Para isso ouvimos alunos, professores e o profissional de informática "residente" na escola. É a partir desse olhar que se elabora o presente trabalho, desenvolvido em duas linhas de investigação: a observação do espaço da escola e a escuta dos seus integrantes. Realizamos reuniões e entrevistas para que os agentes da comunidade escolar pudessem expor as expectativas e frustrações que acompanham a aquisição e manutenção de equipamentos tecnológicos. Os principais referenciais teóricos utilizados foram: Foucault(2003), Deleuze(1992), Machado(2000;2002), Casement e Armstrong(2001) e Cambraia(2013). Trata-se de uma pesquisa qualitativa, que utilizou a análise textual discursiva. Teve como campo empírico sete escolas do município de Ijuí. Através da análise dos relatos diagnosticamos a necessidade de que as escolas construam seus próprios caminhos com a informática e educação, priorizando a produção do conhecimento.
\end{abstract}

Palavras-chave: Cultura informática na escola. Informática educacional. Capacitação de professores

\begin{abstract}
This research about computer literacy refers to school pedagogical practices. To this end, students, teachers and the "resident" computer professional in school have been interviewed. From this perspective, the study was developed in two lines of research: the observation of the school context and listening to its members. Meetings and interviews were carried out so that the school community agents could express their expectations and frustrations concerning the acquisition and maintenance of technological equipment. The main theoretical references for the study were: Foucault (2003), Deleuze (1992), Machado(2000; 2002), Casement and Armstrong(2001) and Cambraia (2013). This qualitative research used discursive textual analysis. The field study included seven schools in the city of Ijuí. The analysis of the reports demonstrated the need for schools to build their own ways of dealing with computers and education, giving priority to the production of knowledge.
\end{abstract}

Keywords: Computer culture in school. Educational computing. Teacher training.

"Professor do Curso de Licenciatura em Computação do Instituto Federal Farroupilha, IF-Farroupilha, Brasil. Doutorando em Educação nas Ciências - Computação pela Universidade de Ijuí (UNIJUí) 


\section{Introdução}

Vivemos em uma sociedade imersa em tecnologias. Um computador pode ser encontrado em diversos outros dispositivos, como celulares, tablets, televisores e outros, que possuem, de forma embarcada, um computador em seu interior, permitindo inúmeras possibilidades de programação. A cada dia a presença dessas tecnologias em diversos setores da sociedade é ampliada, na forma de interfaces que servem de comunicação entre as pessoas, instituições e objetos, que, nesse texto, denominamos de Tecnologias de Informação e Comunicação (TIC) ${ }^{1}$. Então, cada vez mais, conhecemos novos dispositivos, que são modos de facilitar e ampliar o acesso às informações e a comunicação em nossas vidas.

Nesse contexto, surgem desejos, crenças, fantasias e frustrações a respeito do uso das TICs, que são reproduzidos através de discursos que chegam à escola pelos pais, professores, alunos e profissionais de informática. Analisar esses discursos, entender as expectativas e frustrações que acompanham a aquisição e manutenção de equipamentos, como influenciam no desenvolvimento de uma cultura informática e, ao mesmo tempo, ressaltar a importância dessa cultura para a formação de cidadãos participantes da produção do conhecimento é objetivo desse artigo.

A partir do momento em que as escolas de Educação Básica iniciaram a aquisição de TICs, a principal preocupação diz respeito à questão: o que fazer com esses instrumentos? São inúmeras as expectativas, mas como alcançá-las, constitui-se em dúvida da comunidade escolar. Então, esse dilema é repassado aos profissionais de informática², que tratam de possibilitar que as TIC sejam utilizadas com o máximo de aproveitamento: seja trabalhando com manutenção dos equipamentos, avaliação e instalação de softwares, articulação com professores para criação de projetos interdisciplinares e inclusão di-

\footnotetext{
${ }^{1}$ Nas próximas referências usar-se-á a abreviatura de TIC para Tecnologias de Informação e Comunicação, que nesse texto faz referência aos computadores, notebook, tablets, celulares, etc.

${ }^{2}$ Foi utilizado o termo profissional de informática devido ao autor do artigo ser um Bacharel em Informática, ou seja, um profissional de informática, que desenvolve um trabalho com as TIC em escolas, assumindo o papel de professor. Por isso, em inúmeras vezes, se faz uma crítica e uma autocrítica. Em que o autor se inclui como parte do processo, pois seu olhar também contribuiu para a constituição dessa cultura informática presente nas escolas. Da mesma forma que faz uma autocrítica, emite suas observações a respeito da incorporação dos recursos tecnológicos na escola para que o próprio leitor faça uma reflexão sobre o tema.
}

gital de professores e alunos. Contar a versão desse profissional na constituição da informática na educação significa mostrar uma concepção, que pode ser instituída ou esquecida em relação à utilização de TICs.

Na tentativa de mostrar a influência do profissional de informática na estruturação da informática educacional é que foi organizada a pesquisa empírica, que contou com a participação de um total de sete escolas. Destas, duas são particulares e cinco públicas, com infraestrutura variada, desde escolas com seis computadores até com sessenta computadores conectados à Internet. A diversidade das realidades propiciou uma descrição detalhada de como e por quais meios se manifesta a cultura informática (CAMBRAIA, 2013) nas escolas. Todas as escolas estão situadas no município de Ijuí, localizado na região noroeste do Estado do Rio Grande do Sul.

Um dos critérios na escolha das escolas foi a não existência de vínculo com as mesmas, pois o desejo era deixar as pessoas à vontade para expor suas expectativas, sonhos ou frustrações em relação as tecnologias na educação.

A coleta de dados foi realizada em épocas diferentes. Em um primeiro momento, a intenção era utilizar apenas as entrevistas realizadas em 2010, que são reuniões com a comunidade escolar para discutir sobre a Informática e a Educação. Na escrita desse trabalho, se retornou em algumas escolas para entrevistar os professores que desenvolvem projetos que utilizem as TIC.

A descrição da obtenção desses dados será feita por ordem cronológica, conforme a realização da coleta dos dados (2010 e 2013). Assim, foi iniciado por 2010, que representam as escolas " 1 ", "2" e "3". Em 2013, além das escolas "4" e "6", também foi entrevistado um professor da escola "7".

Para a coleta de dados realizada em 2010 foram organizadas reuniões em três escolas de Ijuí. Inicialmente, foi feito um contato com a equipe diretiva expondo as intenções da pesquisa e nosso propósito de que todos os interessados pelo assunto participassem. A única restrição feita foi a de que somente pessoas vinculadas ao Ensino Fundamental participassem das reuniões, a fim de evitar que a pesquisa acabasse por ser vinculada a cursos técnicos e/ou ao mercado de trabalho, o que não era a intenção. 
Nessas reuniões, houve maior participação de professores, pois foi oferecido o horário de reunião dos mesmos para a realização das discussões. Os encontros iniciavam com uma fala em relação à pesquisa e, ao mesmo tempo, era possibilitada a discussão em relação ao assunto. Então, é uma pesquisa de caráter qualitativo, uma vez que:

Ela se preocupa, nas ciências sociais, com um nível de realidade que não pode ser quantificado. Ou seja, ela trabalha com o universo de significados, motivos, aspirações, crenças, valores e atitudes, o que corresponde a um espaço mais profundo das relações, dos processos e dos fenômenos que não podem ser reduzidos à operacionalização de variáveis. (MINAYO, 1996, p.21-22)

Nesse sentido, foi realizada uma Análise Textual Discursiva (MORAES, GALIAZZI, 2013) como possibilidade de analisar os discursos dos professores de forma que confluam em resultados de pesquisa, ou seja, a escrita desse artigo ocorreu de acordo com as entrevistas, pois a partir delas foram construídas categorias, que originaram nos principais tópicos do texto.

As questões elencadas serviram como um guia de ordem geral, com a intenção de focar a discussão, não para a presença de computadores nas escolas, mas para uma dimensão mais cultural das TIC em nossas vidas. Conforme ocorreram as discussões, outras questões foram formuladas, tanto pelo pesquisador, quanto pelos próprios professores entrevistados. Assim, em cada escola, aconteciam diferentes discussões, de forma que foi possível obter um maior entendimento da organização, expectativas e frustrações das escolas em relação às TIC.

Para facilitar e aproveitar ao máximo essas discussões, as escolas foram referenciadas de forma numérica. Como essas entrevistas foram realizadas em grupos, os sujeitos apenas foram identificados como professores, pais ou funcionários e em que escola trabalham. Assim, uma caracterização de cada instituição foi necessária para possibilitar um maior entendimento de suas ações e anseios.

A escola "1" pertence à rede pública e possui Ensino Fundamental. É interessante ressaltar que essa escola foi a única em que, além dos professores, também participaram pais, alunos e funcionários.

A escola " 2 " é caracterizada como uma escola comunitária de Ensino Médio e Técnico. A participa- ção dessa instituição ocorreu devido ao convite feito pela direção, que havia participado do encontro com a escola "1" (a pessoa que está na direção da escola " 2 " é professora na escola “ 1 "). Assim, para o encontro se colocou como critério apenas a participação de professores envolvidos com a educação básica.

A escola "3" pertence à rede particular de ensino e é a escola que apresenta melhor infraestrutura. Nessa escola, além de conversar com o grupo de professores realizamos uma entrevista com a professora que auxilia no trabalho com as TIC na escola. Por isso, a fim de facilitar a identificação da professora entrevistada, adotaremos o nome fictício de Betina. A escola possui os seguintes níveis de ensino: Educação Infantil, Ensino Fundamental, Ensino Médio.

Das escolas acima referenciadas apenas uma não possui acesso à Internet, a escola “1”. O número de alunos varia entre 100 a 600. A descrição da escola tem a intenção de evidenciar as diferentes realidades de cada instituição pesquisada, o que pode permitir uma compreensão mais detalhada da presença do domínio e da cultura informática ${ }^{3}$, independente dos equipamentos encontrados.

Além das escolas já descritas, também foram entrevistadas mais três, todas da rede pública de ensino. Essas obtiveram laboratórios de informática com recursos do $\mathrm{MEC}^{4}$ através do PROINFOs. O número de alunos varia entre 500 a 2000 alunos. Para cada escola foi atribuído um nome fictício, bem como para a pessoa entrevistada na mesma. Na escola "4", a professora entrevistada foi chamada de Neuza; na escola " 5 ", professora Sônia; e na escola "6", professora Juliana.

Durante a escrita desse artigo, surgiu a necessidade de buscar um melhor entendimento sobre alguns aspectos que se mostravam relevantes para a pesquisa. Assim, no ano de 2013, se retornou às escolas "4" e "6", para entrevistar outras professoras, que aqui serão chamadas pelos nomes de Mara (escola “4”), Lurdes e Janice (escola “6”). Ainda, somou às anteriores a escola "7", que se enquadra nas mesmas características das escolas "4", "5" e "6".

\footnotetext{
${ }^{3}$ Ambos os conceitos são descritos no artigo de autoria de Adão Caron Cambraia, intitulado "Domínio e Cultura Informática na Escola", publicado na Revista Linhas. v. 14, n. 27 (2013). Isso significa que esses artigos se complementam e uma leitura do artigo referenciado auxilia na compreensão da abordagem dada aos conceitos de domínio e cultura informática.

${ }^{4}$ Ministério da Educação e da Cultura.

${ }^{5}$ Programa Nacional de Informática.
} 
Nesta, a professora entrevistada foi referenciada com o nome de Mirian. Apenas as escolas " 4 " e "6" possuem acesso à Internet.

Todas as discussões foram gravadas em áudio ou vídeo e, posteriormente, transcritas. As gravações em vídeo permitiram a observação das fisionomias das pessoas, além de suas falas, possibilitando um maior detalhamento das euforias, angústias e frustrações ${ }^{6}$. Com isso, elencamos os principais pontos abordados nessas conversas, com o intuito de que essa descrição amplie as discussões da temática aqui abordada.

Dessa forma, no primeiro tópico intitulado "A escola como multiplicadora de "novas tecnologias", descrevemos o desejo e o esforço da maioria das instituições para adquirirem computadores/tablets/ internet e como possibilitam a disseminação das "novas tecnologias".

No tópico 2, intitulado "Os multiplicadores de "novas tecnologias", mostramos que os agentes escolares se tornam potenciais disseminadores de tecnologias, pois, desenvolvem talvez, inconscientemente, um mecanismo que determina e, até mesmo, impulsiona as pessoas e instituições a se empenharem nessa aquisição.

No tópico 3, intitulado "As expectativas em relação às "novas tecnologias", descrevemos a esperança depositada nas TIC para resolver os problemas da educação e, ainda, garantir aos alunos um acesso ao mercado trabalho, mediante um domínio desses instrumentos.

No tópico 4 analisamos as diversas capacitações demandadas na escola para responder as expectativas iniciais. Esses tópicos abrem caminho para entendermos a constituição de cenários da informática educacional vivenciados nas escolas, que serão também descritos no tópico cinco.

\section{A escola como multiplicadora de "novas tecnologias"}

A computação se apresenta na forma de diversos aparelhos que acabam por integrar-se à vida das pessoas ${ }^{7}$. Esse é um movimento que engloba toda a

\footnotetext{
${ }^{6}$ Ao descrever a fala de cada entrevistado, optamos por transcrever na íntegra, na forma como apareceram nas entrevistas.

${ }^{7}$ Verificar o artigo "Domínio e Cultura informática na escola", publicado na Revista Linhas v. 14, n. 27 (2013), Tópico 4, - Cultura informática como matriz sócio técnica.
}

sociedade, seja adquirindo tais aparelhos ou desejando-os. Então, retratar esse movimento, em especial nas escolas de Educação Básica, é intenção neste tópico.

Dificilmente encontramos uma escola que não tenha interesse em adquirir tecnologias de última geração. Se possuir recursos financeiros, essa disponibilização é facilitada, pois, conforme afirma o(a) diretor(a) da escola "3": "A intenção era colocar um laboratório de informática, porque a informática estava ai e a gente tinha que, de repente, incrementar a escola, inovar né, com o que tem de tecnologia". Com isso, fica evidente que a escola almeja a novidade a título de experiência. De certa forma, essa introdução tecnológica se autoriza por ser novidade; suspendemos nossos questionamentos, para fazer a experiência do "novo". Portanto, se o argumento que justifica a introdução das TIC é a novidade, consequentemente, também justifica as inúmeras atualizações.

Esse interesse em adquirir computadores também é evidenciado nas escolas que não possuem recursos financeiros. Estas também não medem esforços para disponibilizar as TIC, conforme relata um(a) professor(a) da escola "1", ao abordar os obstáculos que enfrentam para proporcionar tais equipamentos à comunidade escolar: "Aqui no meio dos bairros, onde nós derrubamos um banheiro para construir um laboratório de informática, e eu penso quantas pessoas vão poder usufruir disso".

Ambos os depoimentos confirmam que se faz nas escolas o possível para adquirir as TIC, pois transparece uma certa urgência por essa aquisição. Além desse esforço, as escolas que recebem os laboratórios de instituições governamentais ou ONGs (Organizações Não Governamentais) não são privadas de desembolsar imensos valores para adequar seus espaços, de acordo com as exigências que lhes são impostas, conforme afirma a professora Juliana da escola "6": "Nós recebemos os computadores do $M E C$ e também teve uma enorme participação do CPM da escola. Tivemos que buscar recursos financeiros para efetivar a instalação desse laboratório, tinha uma série de exigências, materiais, espaço, instalação de rede e softwares".

A partir desse depoimento, é pertinente ressaltar que o desenvolvimento desses equipamentos muda a cada dia e "a cada novo progresso tecnológico, 
as escolas são forçadas a ensinar as novas técnicas aos seus alunos" (CASEMENT\& ARMSTRONG, 2001, p.15), o que obriga as instituições a entrarem em uma corrida por atualizações, pois equipamentos que hoje são de última geração, amanhã estarão obsoletos. Conforme a professora Lurdes da escola "6", "precisamos ampliar o número de máquinas, sem contar a melhoria de cada uma". Assim, de acordo com a mesma professora, "queremos informatizar a biblioteca, pensei que podiamos comprar computadores novos para o laboratório $e$ mandar esses para a biblioteca". Com esse relato, demonstra-se a necessidade existente nas escolas em possuir máquinas mais novas para que possam diversificar as atividades e transformar o laboratório de informática em um ambiente requisitado por todos.

Algumas escolas demonstram que já incorporaram e, de certa forma, aceitaram essa aceleração para manterem-se "atualizadas", conforme relata um professor da escola "3": "estamos começando, eu acho que esse seria o avanço maior. A gente não vai se acomodar, quando a gente tiver isso, não vai ser o suficiente e assim vai", ou seja, existe uma consciência frente às permanentes atualizações tecnológicas, às quais precisaremos nos submeter, que inicia com a aquisição dos equipamentos e continua com a constante renovação dos diversos softwares e dos aparelhos que, cedo ou tarde, tornam-se obsoletos.

Dessa forma, as atualizações e aquisições de novos dispositivos para incrementar tecnologicamente a escola podem acontecer a todo momento. Conforme ressalta a professora Betina da escola "3": "A escola tem uma vontade muito grande de melhorar sempre nessa área [...], precisamos de máquinas novas. Na verdade nós temos um canal bem aberto com a direção, coordenação, então a gente consegue passar isso e sempre, na medida do possivel, é adquirido. Claro que a vontade da escola é que se faça sempre o melhor, mas nem sempre é possível. Estamos mudando agora um laboratório, mas todo ano tem investimento".

A concepção de que disponibilizar o melhor necessita de investimentos diários - acredita-se que o melhor seja tudo que é de última geração - é compartilhada pela maioria das pessoas da comunidade escolar, como é evidenciado nas falas que seguem no decorrer do texto. Então, na medida em que temos essa concepção, a tendência é aumentar os investimentos, pois são ofertados novos aparelhos de acordo com o interesse das grandes corporações (CAMBRAIA, 2013). Acabase aceitando nas escolas a entrada em um círculo vicioso, devido a uma espécie de pressão advinda do cotidiano ou novas exigências que a atual sociedade impõe para nossas vidas. Conforme uma professora da escola "1": "tínhamos alunos que saíam da escola, voltaram porque agora tem computador", ou seja, as TIC são impostas para a escola como uma questão de sobrevivência.

Nas escolas, dessa forma, a informática é recebida e inserida no Projeto Político Pedagógico (PPP) como algo inteiro e bruto, pois não está contemplada no PPP de nenhuma das escolas entrevistadas $^{8}$. Acabamos por esquecer que o projeto político-pedagógico deve representar a singularidade de cada escola, que o professor precisa se colocar como um co-autor do projeto, baseado em convicções específicas de cada contexto, que envolvem elementos simbólicos das mais diversas naturezas. No entanto, conseguimos, apenas, revestir a informática com uma "camada protetora". Em outras palavras, criamos uma sistemática de aproximação e distanciamento, atribuindo a responsabilidade por estes espaços a algumas pessoas que têm como função responder pelos mesmos e promover o desenvolvimento de atividades para que tais espaços sejam utilizados.

Assim, conforme a professora Lurdes da escola "6", "ainda temos muito que alcançar na escola. Gostaríamos de atingir mais professores, mas isso é uma coisa que nós teremos que puxar mais, fazer mais capacitações". Evidencia-se, então, a única alternativa para os coordenadores de tecnologias educacionais ${ }^{9}$ : criar estratégias para garantir a ampliação do número de usuários na escola. Os profissionais que atuam no laboratório de informática têm a função de assegurar que esse espaço não fique ocioso. Assim sendo, a todo o momento precisam

\footnotetext{
${ }^{8}$ Depoimento dos próprios professores

${ }^{9}$ Não existe um cargo específico de coordenador de tecnologias educacionais, mas em todas as escolas entrevistadas existe uma pessoa responsável pela articulação das TIC à Educação. Em algumas escolas esse espaço foi assumido por profissionais de informática. Em outras por professores de alguma disciplina que se dispunham em estudar e pesquisar sobre esse tema. Em ambas as situações esses profissionais são vistos como alguém que responde pela articulação da informática com a educação.
} 
estar trazendo para a escola novas ideias, bem como "novas tecnologias", obviamente, quando as condições financeiras de cada escola permitirem.

Diante disso, as escolas perdem a iniciativa, pois precisam estabelecer vínculos com governos e/ ou instituições privadas, visando a arrecadação de fundos, para manutenção (que já é onerosa) e para a renovação de equipamentos. Evidencia-se isso na afirmação de um professor da escola "1": "Os nossos alunos mexem no computador, mas novidade nenhuma. Então, a tecnologia morreu ali [...], o aluno quer fazer coisa nova. Mas, a gente não tem como dar, não tem condições financeiras e daí também cria uma angústia". Com isso, percebemos que a satisfação alcançada com o novo é momentânea, pois a novidade é aquilo que não se possui e não é mais o caso dos computadores, pelo menos em algumas escolas. Então, a novidade passa a ser outra tecnologia.

Ilustra-se, dessa forma, o outro lado das mais variadas atualizações, que não ocorrem somente no momento em que o hardware e o software se tornam obsoletos, mas quando as possibilidades de novidade se esgotam. Assim, sempre precisaremos estar em estado de alerta para o movimento da cultura informática como matriz sócio-técnica (CAMBRAIA, 2013), pois é a forma encontrada de manter acesa a chama da motivação, que precisa a todo o instante ser induzida, para continuar brilhando. Uma das formas de promover essa motivação é a atualização, no sentido de tentar alcançar as tecnologias de última geração. Assim, o professor da escola "1" explica que "os alunos vêm com uma expectativa em relação à informática, a escola não tem recursos e então não conseguimos corresponder". Isso deixa transparecer o quanto é necessário se empenhar para responder a tais expectativas, pois cada vez precisa de mais investimentos. Conforme a professora Mirian da escola "7", "nós desejamos melhorar as TICs, mas sempre esbarramos no financeiro, se não fosse isso poderíamos explorar muito mais", ou seja, nesse caso, para a professora, as dificuldades financeiras implicam em limites pedagógicos.

Ao se definir o domínio como prioridade, a todo o momento sentimos uma certa limitação. A professora Lurdes da escola "6" diz: "o laboratório de informática ainda está limitado e precisamos nos atualizar também", o que significa que os professores desejam atingir o melhor da utilização de computadores. Então, busca-se alcançar esse melhor através da busca da novidade, pois "um novo instrumento tecnológico sempre acaba por relegar o antigo à condição de mero entulho. A transferência de tais juízos para o terreno educacional seguramente é indesejável" (MACHADO, 2000, p. 34). Assim, no momento em que se define uma forma de utilização e se percebe que a mesma não responde às expectativas da comunidade escolar, questionam-se e promovem-se, nas escolas, mudanças diversas (de equipamentos, de softwares e de pessoas), na tentativa de "acertar" a estratégia de utilização dessas máquinas. $\mathrm{O}$ (a) professor(a) da escola "3" descreve a situação: "montamos o laboratório 1 e aí a gente não sabia o que fazer, contratamos uma professora que tinha feito uma pós em informática educacional [...] dai compramos joguinhos [...] mas, a criança está a mil. E, começou temos que comprar joguinhos, comprar joguinhos. Passou um ano e percebemos que não era bem isso.[...] Depois de muitos estudos, cursinhos dentro da escola e fora da escola, fizemos até algumas tentativas de criar alguma coisa em termos de software educacional, foi uma motivação. Mas, a gente foi percebendo com o tempo que alguma coisa tinha que mudar".

Essas várias alterações têm o objetivo de alcançar um modelo de utilização de computadores que satisfaça um maior número de pessoas da comunidade escolar. Se esquece que a alfabetização tecnológica tem a ver com o provisório e não com o fixo (CAMBRAIA, 2013), ou seja, não existe um modelo de utilização de computadores que satisfaça a todos e, na medida em que nos empenhamos em alcançar esse modelo, assumimos a cultura do consumo. Assim, reproduzimos a cultura consumista vigente na sociedade. Ao invés de criticá-la, a potencializamos.

Dessa forma, ao desejarmos que as TIC sejam usadas de forma maciça e prevalecendo o discurso do domínio, estamos formando apenas novos consumidores. Ao invés de promover uma democratização do ensino, conforme Machado (2002) estamos condicionando justamente o contrário, uma elitização do ensino, no sentido de que somente pessoas altamente qualificadas conseguem produzir os materiais a serem utilizados. Nesses casos, os recursos tecnológicos "favorecem um controle social, através da manipulação dos centros de produção" (MACHADO, 2002, p.99) e a maioria 
acaba sendo apenas consumidores de tecnologia, incapazes de gerar suas próprias oportunidades.

Ao assumir essa tendência, as escolas colocam suas comunidades frente a uma tecnologia, de modo que cada indivíduo precisará assumir para si a responsabilidade sobre suas atualizações. Promovemos, então, uma espécie de endividamento, pois precisamos correr atrás para saldar a dívida de "conhecimento". Diversas pessoas da comunidade escolar, diante da insegurança que o computador pode causar, saem à procura de cursos de informática com a intenção de obterem o domínio tecnológico desejado. Primeiro, os cursos mais corriqueiros, como os de informática básica. Depois, começa a aparecer uma diversidade de possibilidades, que não tem fim. Nesse sentido, o(a) funcionário(a) da escola "1" relata sobre o curso de informática que seu filho frequentou: "Coloquei ele na primeira parte. Veio para casa com o programa do segundo. Ai a gente achou que ele ia fazer o primeiro e ia aprender o suficiente. Mas não, teve que fazer mais alguns". Adquire-se assim, uma dívida impagável (DELEUZE, 1992), pois o domínio desejado, dificilmente é alcançado. Independente da eficiência do treinamento recebido, possivelmente muitas informações são esquecidas com o passar do tempo, sem contar com a estratégia dessas empresas produtoras de tecnologia ${ }^{10}$ em imprimir modificações na informática a todo o momento.

Esse alerta não equivale a dizer que tenhamos que fechar as portas para as TIC. Mas que precisamos ter cuidado para não criarmos a confusão de acreditar que simplesmente disponibilizando as "novas tecnologias", estaremos atualizando velhas formas de trabalho. Não é a mera substituição do quadro negro por um quadro eletrônico que garante a elaboração do conhecimento. A produção cognitiva não existe sem uma produção de subjetividades (PELLANDA, 2000). Então, a apropriação das tecnologias pela educação perpassa pelo entendimento de que as TIC “operam no núcleo da subjetividade humana, não apenas no seio de suas memórias, da sua inteligência, mas também de sua sensibilidade, dos seus afetos, dos seus fantasmas inconscientes" (GUATTARI, 1992, p. 14).

\footnotetext{
${ }^{10}$ Como por exemplo, a Microsoft.
}

\section{Os multiplicadores de "novas tecnologias"}

Não precisamos de muito esforço para ouvir as maravilhas que as tecnologias podem proporcionar para nossas vidas. Esses discursos são emitidos e disseminados, até mesmo, por pessoas que não possuem contato direto com as tecnologias e são a força motriz que leva as pessoas e as instituições a valorizarem o domínio tecnológico.

A discussão de como as TIC serão utilizadas começa quando já estão na escola ou quando se recebe a notícia da pretensa aquisição. Na verdade, pouco importa em que momento iniciam-se as discussões, visto que, geralmente, permanecem em torno do que seja possível desenvolver com os computadores. Nesse caso, são recrutados profissionais de informática e/ou da educação. Estes, em grande maioria, deixam de lado as suas disciplinas para pensarem e, algumas vezes, proporem formas de melhor utilizar tais equipamentos como um recurso pedagógico.

Geralmente, os professores não têm alternativas de escolhas entre usar ou não tecnologias. Até porque "quanto mais computadores possuímos à disposição, maior a pressão para utilizá-los" (CASEMENT\&ARMSTRONG, 2001, p. 211), mas uma pressão que não é exercida por uma ou outra pessoa. Não se trata de ordens para que passemos a usá-los, mas um mecanismo disciplinar (FOUCAULT, 2003) que faz com que indivíduos "se encontrem presos numa situação de poder de que eles mesmos são os portadores" (idem, p. 166). Eis a pressão que cada um exerce sobre os outros e sobre si, conforme o(a) professor(a) da escola "2": "essas tecnologias pra mim são um bicho de sete cabeças [...], mas vou ter que aprender, vou ter que aprender pra usar em minha aula. Eu preciso aprender".

Tal depoimento ilustra a cobrança que o próprio sujeito exerce sobre si mesmo, sendo reiterada por outro professor da escola "2": "os professores que chegam para estagiar não sabem informática e eu vejo isso como uma falha". Assim, os professores não têm a possibilidade sequer de escolher se desejam ou não usar as TIC. Isso lhes é exigido. E, na medida em que novos professores chegam à escola sem alfabetização tecnológica, desconsidera-se que podem ainda não estar seguros do conhecimento de sua própria área e aponta-se a 
dificuldade com a tecnologia como falha, ou seja, os professores são colocados em uma situação que não lhes permite a liberdade de escolha. Segundo Foucault (2003), essa é uma forma de poder exercida por cada indivíduo, isto é, um panóptico reproduzido para toda a sociedade.

Nesse panóptico, o olhar é que controla, faz com que cada indivíduo seja "visto, mas nunca veja; seja objeto de uma informação, nunca sujeito numa comunicação" (FOUCAULT, 2003, p.166). Assim, obriga as pessoas a desempenhar determinados papéis, de acordo com padrões pré-estabelecidos na sociedade, sem precisar de um poder centralizador que o pressione, pois o "outro" 11 faz esse papel. Ninguém precisa falar, mas todo mundo vê. Esse olhar faz com que a aquisição e a utilização de computadores, assim como as diversas atualizações, tornem-se necessidades imediatas. Faz com que tracemos metas e prazos para realizarmos nossa alfabetização tecnológica, procuremos, o mais rápido possível, por alguém que possa nos ensinar a manusear as TIC. Faz com que o professor, que não utiliza novas tecnologias, fique em silêncio; mesmo quando tem vontade de dizer que não gosta ou quando declara sua insatisfação, busca aprender a manusear o computador ${ }^{12}$.

Assim, cada olhar é uma peça desse mecanismo que "em vez de se apropriar e de retirar, tem como função maior 'adestrar'; ou sem dúvida adestrar para retirar e se apropriar ainda mais e melhor" (FOUCAULT, 2003, p.143). Instiga-se, dessa forma, as pessoas a usarem o computador a qualquer custo: a escola para ser boa, o professor para ser eficiente, o aluno para construir uma expectativa de futuro. Enfim, a comunidade escolar faz um enorme esforço para entender como utilizar tais equipamentos.

Acabamos produzindo um discurso que permite um questionamento, que normaliza a presença de computadores em nossas vidas e transmite um sentimento de constrangimento e anormalidade para aqueles que não desejam ou não dispõem dos equipamentos. Esse questionamento está presente no cotidiano de cada um, quando perguntamos às pessoas se possuem ou não computador. Mesmo que

\footnotetext{
${ }^{11}$ Não necessariamente uma segunda pessoa, mas "eu mesmo".

${ }^{12}$ A minha experiência em trabalhos nesses espaços permitiram ouvir os professores que afirmavam não gostar de utilizar o computador e, ao mesmo tempo, que precisavam buscar uma formação para se apropriar desses recursos.
}

a resposta seja negativa, seguem outras perguntas, no desejo de saber por que não possuem. Quando possuímos o equipamento, o questionamento é no sentido de saber o que é feito com o mesmo. Assim, é criada em nossas vidas uma certa representação de status, dependendo exclusivamente do possuir ou não e do tipo de utilização que realizamos (se usamos determinados programas ou não), etc., conforme relata a professora da escola "3": "Fica implícito no ar que o computador é necessário, as pessoas que ainda não têm, elas têm vergonha disso. Inclusive alunos, noto uma vergonha, parece assim de não poder usufruir de uma máquina que já é normal, e como é que eu não tenho? E exigem dos pais, muitas vezes, essas máquinas têm que ter em casa, até para mostrar como objeto de valor. Muito mais que uma jóia, parece que o computador te dá um certo status".

Então, o interesse em implantar as TICs na escola parte dos diferentes agentes da comunidade escolar: pais, alunos, professores, direção. Conforme ressalta um pai e professor da escola "1": "quero que meu filho aprenda a usar o computador, eu priorizo". Qualquer pessoa pode exercer influências para que ocorra uma permanente atualização. Mesmo pessoas que não se encontrem diretamente envolvidas com o ambiente escolar, podem influenciar quem está, pois ajudam a passar a ideia de que o domínio dos computadores é sinônimo de sucesso acadêmico e que não tê-los, pode fazer com que nossos filhos "sejam ultrapassados, terminando intelectualmente incapazes" (CASEMENT\&ARMSTRONG, 2001, p.70).

Assim, não precisamos de muito esforço para mobilizar uma quantidade considerável de pessoas que desejam promover a alfabetização tecnológica, como relata o professor da escola "1": "temos a Escola Aberta para a Cidadania, abrimos quatro turmas de informática e tem fila de espera. Neste grupo tem gente de 50, 40 e até de 8 anos de idade". Isso confirma a intensa procura pelo aprendizado de como manusear computadores e evidencia que esse movimento atinge todas as faixas etárias, ou seja, não se trata de influenciar apenas uma determinada geração, mas uma sociedade inteira.

Não restam alternativas para as escolas: adquirem os equipamentos ou correm o risco de comprometer seu sentido como espaço de formação perante suas comunidades, pois muitas expectativas circulam 
nos educandários e também no restante da sociedade quanto à utilização de TIC.

\section{As expectativas em relação às "novas tecnologias"}

Para o desenvolvimento deste tópico, descrevemos as expectativas que os professores depositam nas TIC. Apesar de aparecerem em diversos outros pontos do texto, neste momento salientamos as expectativas evidenciadas como sendo de maior relevância à comunidade escolar.

Uma expectativa bastante presente nas escolas é de que as TIC despertem nos alunos maior interesse pelos estudos, conforme afirma uma professora da escola "2": "Fiz uma gincana de exercicios sobre um assunto que trabalhei na semana passada e os alunos usaram o computador, é uma maravilha! Mas sem o computador eles não teriam vibrado e eu não teria captado a atenção deles". Esse depoimento reforça o aspecto de que a máquina é uma forma de atrair mais a atenção e interesse dos alunos, o que sem a mesma seria impossível. Da mesma forma, a professora Sônia afirma que "colocar imagens, vídeo, enfim deixar um trabalho mais bonito [...] o aluno se empenha mais em fazer a pesquisa" (escola "5"), ou seja, ambos os professores afirmam que a máquina possui recursos que atrai os alunos e torna a educação mais prazerosa. Sendo assim, a informática é vista apenas como uma máquina de ensinar. Confere-se, dessa forma, aos computadores a possibilidade de oportunizar uma aprendizagem mais eficiente, ao passo que "se não ficarmos atentos e não buscarmos maiores conhecimentos dentro da informática, nós estaremos perdendo para os alunos" (professora, escola "3"). Essa declaração da professora estabelece uma espécie de competição entre usuários e não-usuários, dando aos primeiros toda a vantagem em relação aos demais. De certa forma, deixa transparecer que se o professor não for um usuário, não tem alternativas. Como se não possuísse um conhecimento que o coloca nesse lugar e dependesse somente das máquinas para desenvolver suas atividades.

Além disso, a crença de que as TIC sejam uma alavanca para o mercado de trabalho é um discurso mais explicitamente identificado nas comunidades carentes, pois segundo o(a) professor(a) da escola "1": "são famílias pobres e não têm computador em casa e têm todo o direito de ter acesso, quando for ao mercado de trabalho, o aluno vai preparado". A mesma expectativa é ressaltada pela professora Neuza, da escola "4", ao justificar que a presença das TIC na educação tem a intenção de "dar assessoria para que os alunos tenham condições de ir para um trabalho melhor". Nesse caso, representam uma esperança em relação à conquista de um emprego estável $^{13}$ e bem remunerado, na medida em que o domínio do computador prevaleça.

$\mathrm{Na}$ tentativa de dar conta dessas expectativas, as escolas se empenham em adquirir computadores. Assim, desencadeia-se uma série de novas exigências no âmbito educacional. Dentre elas, a capacitação dos profissionais que terão a responsabilidade de articular esse uso nas escolas, bem como a formação dos demais professores, que serão os protagonistas, juntamente com os alunos, da informática na educação.

\section{A capacitação do profissional para atuar com a informática educacional}

Geralmente, antes de iniciar a utilização dos computadores, a comunidade escolar se preocupa em encontrar um profissional que se responsabilize e organize os projetos. Dificilmente é encontrado alguém que esteja preparado e que se disponha a assumir tal desafio, pois implica em mudança de rotina, conforme relata a professora Mirian da escola "7": "é muito mais fácil trabalhar na sala de aula do que trazer os alunos para o laboratório de informática". Nesse sentido, algumas escolas logo que adquirem as TIC optam "pela contratação de professores com formação em Informática Educacional" (professora, escola "3") ou pessoas com a formação em informática, com a intenção de iniciar imediatamente a utilização de computadores. Em outras escolas, um professor do atual quadro docente é convidado para desempenhar o papel de articulador do uso das TIC. $\mathrm{Na}$ medida do possível, escolhe-se um usuário e/ou alguém que demonstre gostar de informática. Mas, quando essa pessoa não é encontrada, conforme a professora Juliana, essa escolha é "como se jogassem uma batata quente de mão em mão, professor

\footnotetext{
${ }^{13}$ Verificar o artigo "Domínio e Cultura informática na escola", publicado na Revista Linhas v. 14, n. 27 (2013), Tópico 5.5 - "O discurso do domínio traz precocemente para a escola a preocupação com o mercado de trabalho".
} 
nenhum queria abraçar isso [...] eu mostrei interesse e a direção insistiu para que a gente abraçasse isso". Assim, aos poucos, se constituiu a equipe de coordenadores do laboratório de informática educacional da escola.

$\mathrm{Na}$ medida do possível, esses profissionais efetuam suas capacitações como a professora Sônia: "fiz um curso de três semanas, [...] em torno de 120 horas" (escola "5") para desenvolver projetos interdisciplinares utilizando as TIC, e complementa que "no curso [...] trabalhava bastante tempo em cima da máquina, mas sempre com um objetivo, uma pesquisa por trás. A partir dai íamos aprendendo a usar os aplicativos", ou seja, foi visualizado como e o que poderia ser desenvolvido com as TIC, tendo como principal meta a utilização pedagógica, que se ressalta no depoimento da professora Mirian: "escolhemos um assunto e definimos nossas dúvidas e certezas em relação ao assunto, a partir disso, pesquisamos na Internet, depois passamos para o PowerPoint para fazer uma apresentação para os outros professores" (escola "7").

A professora ainda destaca outras atividades que estão no programa da capacitação, como "Word, Excel, fazer páginas e aprender a utilizar diversos programas especificos para cada disciplina" (Mirian, escola "7"). Já a professora Mara, da escola "4", diz: "na capacitação estamos em uma etapa, que estamos fazendo um jornalzinho, depois eu encaminho para o pessoal de português, para fazer um jornal da escola mesmo". Percebe-se, portanto, que esses profissionais docentes passam a ser vistos como os responsáveis pela informática na escola.

Assim, tais profissionais são procurados a todo instante para resolverem questões com as máquinas. No momento em que entrevistava a professora Lurdes, chegou uma professora e falou: "eu vim aqui para aprender a usar esse negócio", que era um endereço de um site de jogos. Ao questioná-la se tais requisições são corriqueiras, ela afirmou: "sempre nos procuram para fazer uma coisa ou outra. Pedem tanta coisa, até para fazer imposto de renda [...], me pedem para ver o e-mail [...], eu sento com o professor e digo para ele como fazer: abre ali, clica aqui". Já a professora Janice, da escola "6", afirma que "tem um espaço para ajudar os professores e a cada reunião mostro coisas". Isso é feito com vistas a promover a alfabetização tecnológica do professor.
De acordo com a professora Neuza, também faz parte do processo de capacitação um "retorno ao núcleo (NTE) ${ }^{14}$ uma vez por mês para dar sequência ao trabalho" (escola "4"), que possivelmente ajuda no andamento do projeto. Ao mesmo tempo em que os coordenadores se encontram e podem trocar experiências, com o objetivo de promover um aprimoramento da proposta, ocorre uma ampliação de cenas de uso do computador na educação.

Além disso, muitos professores, como a Juliana e a Lurdes da escola "6", também procuraram cursos de Especialização em Informática Educacional, na tentativa de ampliar ainda mais o leque de possibilidades de uso dos computadores na educação. Conforme a professora Lurdes: "a especialização me deu mais segurança, aprendemos a instalar mais programas, usar novos acessórios, como WebCam e as redes sociais, que nós nunca tínhamos participado e mandar trabalhos. A pós-graduação foi na mesma linha que a capacitação, que é o trabalho por projetos, incrementou o trabalho da capacitação, pude conhecer mais coisas".

Depois dessa preparação é o momento de efetuar a capacitação dos demais professores. Então, cada escola tem a liberdade de organizar-se de acordo com a disponibilidade e interesse dos mesmos. $\mathrm{Na}$ escola da professora Sônia, "ficamos meio ano no laboratório trabalhando com os professores em grupos e cada grupo escolheu um assunto e fez um projeto, como aprendemos lá no NTE. Ficávamos das 17 h. e 30 min. às 19 h. e também aos sábados" (escola "5"). Esse depoimento mostra o empenho e o esforço dos professores na tentativa de proporcionar uma educação mais qualificada.

Entretanto, conforme a professora Juliana, da escola "6", apesar de tentar dinamizar os horários das capacitações, na tentativa de inserir o maior número de professores possível na proposta, "conseguimos uma média de 13 professores de um total de 80", que é compreensível, pois segundo Pesquisa Nacional da UNESCO (2004, p.197) 41,9\% dos professores brasileiros trabalham em duas escolas ou mais, mesmo assim alguns encontram tempo para realizar suas capacitações. Para dificultar ainda mais, de acordo com a professora Mirian, da escola "7",

\footnotetext{
${ }^{14}$ Núcleo de Tecnologia Educacional, responsável pela formação de professores para a articulação das TIC com a Educação no estado do Rio Grande do Sul.
} 
"existe uma grande rotatividade de professores na escola e os novos geralmente não sabem o que fazer com as TICs". Em quase todas as escolas é salientada a necessidade de proporcionar aos professores capacitações permanentes.

Nas capacitações, segundo a professora Neuza, foi priorizado "como montar um projeto, por exemplo, de química e transportar isso para a tecnologia" (escola "4"). Como as diversas áreas precisavam ser contempladas, a metodologia usada foi adaptada para se encaixar às diferenças. Tanto que, para cada área do conhecimento, é possível desenvolver trabalhos com as TIC, utilizando a metodologia de projetos. Já algumas escolas, conforme a professora Betina, realizam capacitações, como "oficinas para os professores, de apresentação e desenvolvimento de softwares educacionais", na tentativa de fazer com que cada docente passe a construir seus próprios materiais e conheça uma maior diversidade de softwares existentes no mercado. Há escolas que possuem softwares das diversas áreas, de forma que se o professor desejar, encontra algo para utilizar em sua aula. Assim, essas metodologias auxiliam alguns professores na descoberta de possíveis atividades para serem desenvolvidas com as TIC. A professora Neuza, da escola "4", complementa, dizendo que geralmente faz um convite "para que o professor regente vá para o laboratório com seus alunos e ministre suas aulas lá. Nós estamos ai para assessorar esse trabalho. Trabalhamos mais diretamente com o professor, primeiramente, e lá assessoramos os alunos nos computadores, porque nem todos têm o conhecimento, dando assessoria na parte técnica".

Após a capacitação dos professores, a utilização das TIC nas aulas passa a ser a prioridade. Nesse sentido, não são medidos esforços para que o maior número de professores passe a usufruí-las. Segundo a professora Neuza, "nós estamos tentando encantar os professores, fiz uma página descrevendo o que os professores podem fazer com a informática" (escola “4”), pois esta é a grande dificuldade a ser enfrentada no âmbito educacional: fazer com que o maior número de educadores utilizem essas tecnologias. Para isso são descritas atividades que podem ser desenvolvidas com os mesmos.

Na medida do possível, o coordenador permanece no laboratório para auxiliar na parte técnica e pedagógica das atividades propostas. Teoricamente, o coordenador tem a função de realizar a mediação entre tecnologias, alunos e professores, na tentativa de oportunizar um bom andamento da aula. Mas, conforme a professora Sônia, "muitas vezes, nós estamos dando a aula pelo professor, principalmente quando ele não domina o computador" (escola "5"). Da mesma forma, a professora Neuza afirma que " $o s$ professores chegam ao laboratório de informática, largam a pasta deles e tu te vira" (demonstrando indignação em sua fala), segundo a professora "não é assim que é para acontecer, pois o próprio professor é para reger sua aula".

Estes depoimentos nos lembram que podemos estar diante de uma nova versão do tecnicismo ${ }^{15}$, que qualquer pessoa ao se apossar do "livro didático eletrônico" pode ensinar, basta possuir o domínio dos equipamentos para ministrar aulas. Esse mesmo fenômeno, às vezes, pode ser notado em palestras. $\mathrm{Na}$ medida em que a pessoa utilizar meios eletrônicos é vista como alguém que ocupa um patamar superior em relação à outra que opta em não utilizar tais recursos. Como se a presença do equipamento garantisse a qualidade dos argumentos. Diante do exposto, evidencia-se também a dependência existente em relação aos professores que articulam as TIC na escola, pois são os únicos a quem se recorre, caso aconteça qualquer tipo de problema técnico, que implique ou não no pedagógico. $\mathrm{O}$ esclarecimento dos detalhes dos trabalhos realizados no laboratório de informática é a intenção do próximo tópico.

\section{Os cenários da informática educacional}

Descrever as formas de utilização da informática na educação é uma tarefa difícil, talvez algumas serão esquecidas, outras sequer serão conhecidas, pois o que é novo para alguns, é obsoleto para outros. Assim, ao se tratar de cultura informática, apesar de cada escola possuir uma determinada estrutura física, são aplicadas formas

\footnotetext{
${ }^{15}$ Tendência verificada nos anos 70, inspirada nas teorias behavioristas da aprendizagem e da abordagem sistêmica do ensino, que definiu uma prática pedagógica altamente controlada e dirigida pelo professor com atividades mecânicas inseridas numa proposta educacional rígida, passível de ser totalmente programada em detalhes. Assim, o que é valorizado nesta perspectiva, não é o professor e o aluno, mas sim a tecnologia, o professor passa a ser um mero especialista na aplicação de manuais e sua criatividade fica dentro dos limites possíveis e estreitos da técnica utilizada. (Acessado em www.educabrasil.com.br/eb/dic/ dicionário.asp, no dia: 21/09/2014, às 21:05).
} 
de uso semelhantes. Isso mostra que as capacitações realizadas para os professores agora se aplicam aos alunos.

As utilizações das TIC encontradas nas escolas são denominadas aqui como cenários da informática educacional e aparecem organizadas conforme o relato feito pelas diversas escolas que participaram da pesquisa. Esses cenários se misturam e notamos a presença sempre de um ou outro no âmbito educacional e, em algumas escolas, até mesmo todos os cenários podem ser encontrados. Assim, ao abordar um determinado tipo de uso como foco principal da seção, certamente aparecerão outros cenários, que são complementares ou que, muitas vezes, são vistos como complementares, mas no cotidiano escolar se tornam as principais aplicações desenvolvidas, de forma que exigem seções à parte para descrevê-los.

\subsection{Os projetos educacionais}

$\mathrm{Na}$ maioria das escolas onde existem laboratórios de informática, os objetivos dos trabalhos desenvolvidos são semelhantes. Conforme a professora Neuza, "o objetivo não é ir lá ensinar para o aluno o que é um mouse, um monitor, uma tela, CPU [...] trabalhamos os projetos educacionais" (escola “4”), ou seja, utilizar computador como uma ferramenta para promover o aprendizado e, por consequência, segundo a própria professora Neuza, "o aluno aprende a utilizar os recursos do computador, digitando e pesquisando na Internet". Então, concomitantemente aos projetos, ocorre uma alfabetização tecnológica.

Apesar de cada escola valorizar mais a utilização de determinados softwares do que outras, talvez devido à própria disponibilidade dos mesmos, a maioria desenvolve atividades com o que dispõe instalado nos equipamentos, direcionando-os para desenvolver atividades que perpassam pelos conteúdos de cada área. Assim, a professora Juliana relata sobre a experiência de sua escola no laboratório de informática: "em um turno usamos muito a Internet para pesquisa. Fizemos um trabalho, dentro de um projeto de preservação do meio ambiente. Também um trabalho de Educação Artística, a professora trabalhou a questão da Arte, a gente entrou em vários sites referentes a isso, a história da música, da propaganda. Eles estão montando uma propaganda em cima do PowerPoint" (escola “6”)
O depoimento da professora ressalta que a Internet, como meio de pesquisa, pode ser utilizada em diferentes áreas do conhecimento. Sua aplicação como uma ferramenta para agilizar o acesso à informação possibilita que cada disciplina possa usufruir das TIC, bem como do apresentador de trabalhos, que oportuniza a sistematização e socialização das informações. Conforme a professora Juliana, os esforços não foram pequenos para tentar promover, no desenvolvimento desses projetos, maior interdisciplinaridade: "nós propusemos, por exemplo, um trabalho de organização de um jornalzinho. Pedimos que os professores de Língua Portuguesa se envolvessem e procurassem envolver mais turmas, mais disciplinas para agendarmos horários para as turmas no laboratório, não somente nos horários da professora de Língua Portuguesa, como também no horário de Ciências, de Matemática, enfim, no horário daqueles que estivessem envolvidos no projeto" (Juliana, escola " 6 ").

Evidencia-se que o coordenador do laboratório de informática empenha-se na tentativa de promover uma maior comunicação entre as disciplinas. Para isso, articula os professores para desenvolverem atividades voltadas a um mesmo fim, com a esperança de que a desejada interdisciplinaridade aconteça. Com essa intenção, a mesma alfabetização tecnológica dos professores é propiciada aos alunos, pois vinculam-se aos diversos projetos, usos de diferentes softwares, atribui-se a cada um deles um determinado significado de acordo com os objetivos da turma, conforme relato: "os alunos são consultados sobre assuntos de seus interesses, para realizarem um projeto de pesquisa, em grupo. Depois, escrevem as dúvidas e as certezas que o grupo possui sobre o assunto escolhido. A pesquisa é realizada na Internet, eles precisam entregar um trabalho escrito no Word obedecendo as normas da ABNT e organizar as apresentações no Power Point para serem socializadas para o restante da turma (Betina, escola “3”).

A descrição dessas atividades mostra que a capacitação iniciada com a formação de um profissional para articular projetos com as TIC e, mais tarde, dos demais professores, efetivamente foi empregada como uma dinâmica de trabalho nas escolas. 


\subsection{Os jogos eletrônicos}

Dificilmente, entramos em um laboratório de informática que não possua algum tipo de jogo instalado. Então, nesse cenário, desejamos referenciar a aceitação ou não dos jogos eletrônicos na escola, principalmente daqueles que circulam de aluno para aluno, e surgem na maioria das máquinas de um instante para outro.

Nas escolas, geralmente, essa categoria de jogos está presente, pois conforme uma professora da escola "3" "quando os alunos sabem que pretendemos ir ao laboratório, antes de qualquer coisa, começam a pedir jogos". A professora Mirian, da escola "7", complementa que "os alunos são vidrados nesse tipo de jogo, é o que eles mais gostam". Assim, acabam encontrando formas de instalá-los nas máquinas, alguns fazem um download ${ }^{16}$, outros trazem de casa em pendrives, para jogarem na primeira oportunidade que tiverem.

$\mathrm{Na}$ escola, esse tipo de jogo não é visto com bons olhos. Um professor da escola " 3 " afirma que precisa sempre estar negociando com os alunos para desenvolver suas atividades: "a gente tem que conversar e explicar que o objetivo não é jogar, mas utilizar o computador pedagogicamente". Com isso, o cenário dos jogos eletrônicos encontra barreiras. Mesmo assim, sua presença é verificada em quase todas as escolas. Mas nem sempre é bem vinda, conforme uma professora da escola "3": "na verdade, acredito que estamos passando por uma releitura positiva da informática. Antes, a gente ligava a informática com os jogos [...] os alunos iam trabalhar nesse tipo de coisa no laboratório, não tinha muita relação com o que estava sendo feito em sala de aula [...] agora eles estão usando a informática como uma ferramenta, assim eu vejo grandes mudanças, como pano de fundo eles estão aprendendo Word".

Fica evidente, em sua fala, que a professora interpreta como um avanço a passagem da interação dos jogos para a construção em diversos aplicativos, ou seja, deixa-se de interagir para produzir um resultado, que o programa tem pré-construído como, por exemplo, digitar um texto, mudar as fontes e inserir figuras. Outra professora faz questão de salientar que "hoje a gente organiza e eles sentam e sabem como

\footnotetext{
${ }^{16}$ Cópia de arquivos da Internet.
}

iniciar, aonde buscar, o que têm que fazer, mesmo não sabendo ler. Eles estão sabendo usar os recursos da computação nos trabalhinhos". Dessa forma, além de reforçar a concepção da professora citada anteriormente, ainda deixa transparecer, em sua fala, que a escola prioriza o treinamento dos alunos para desenvolverem determinadas tarefas no computador.

Assim, não levamos em conta que as crianças fazem do computador, às vezes, a sua opção preferencial de relação com o mundo (TURKLE, 1997), não somente de lazer. Criam novas amizades, novas relações a partir daquelas pessoas que compartilham com elas esses espaços virtuais. As crianças que jogam os RPGs ${ }^{17}$ ou jogos de rede são capazes de estudar muito para começar o jogo. Então, não podemos dizer que todos os jogos são tolos, pois eles envolvem estudos sérios e compenetrados, que são do reino da fantasia, mas são pesquisas complicadas, que as crianças se dispõem a estudar para ter acesso.

\subsection{Os softwares educacionais}

Nesse cenário, podemos desenvolver atividades utilizando as TIC nos diversos níveis de ensino. Os softwares educacionais são evidenciados com maior intensidade na Educação Infantil e Anos Iniciais e, com menor presença, nos outros níveis de ensino. Atualmente, seria impossível enumerar a quantidade desses softwares que circulam no mercado, pois os recursos multimídia integrados aos computadores deram impulso à venda desses produtos. Com isso, além do aumento da quantidade de opções, a qualidade gráfica melhorou. Dessa forma, sua presença no âmbito educacional facilitou o acesso e uso das TIC, na medida em que atraem a atenção dos alunos e, ao mesmo tempo, permitem desenvolver trabalhos em determinadas disciplinas.

Nesse sentido, segundo a professora Lurdes, "o número de alunos para nós não é problema, [...] na nossa capacitação, ficávamos três pessoas em uma máquina e a gente aprendia e com os alunos também, pois a maioria dos joguinhos tem a opção de desenvolver atividades em dupla" (escola "6"). A professora deixa claro que as atividades com as TIC independem do número de alunos. Tanto que para o público infantil, existem diversas opções de

\footnotetext{
${ }^{17}$ Role Playing Games.
} 
softwares. A descrição da professora Lurdes, da escola "6", ilustra um determinado software e como este é utilizado: "É uma espécie de jogo, mas tem várias atividades. Geralmente dá um retorno ao aluno. Tem um labirinto, com questões, aí o gênio fala com o aluno, vai dando o retorno, quando o aluno erra o programa diz: 'tente outra vez' [...] tem um jogo de memória, um de formar palavras, que tem um conjunto com letras para serem clicadas pelo aluno, cada letra clicada se for a certa vai formando a palavra e construindo uma moto, caso a letra clicada não faça parte da palavra, vai libertando um monstro, assim que a palavra estiver completa, a moto está pronta e o personagem que o aluno conduz sobe na moto e continua o labirinto [...]".

Assim, diversos outros softwares também possuem essa mesma ênfase, que é percorrer um determinado roteiro, passando por diversos obstáculos, que variam entre jogos ou questões de uma determinada área do conhecimento ${ }^{18}$. Com isso, possibilitam ao aluno retornar de acordo com suas dúvidas e avançar conforme conseguir solucionálas. De acordo com a professora Lurdes, da escola " 6 ", esse tipo de software "é colorido, musical e entrete as crianças", ou seja, se deixássemos, permaneceriam nesta atividade o tempo desejado, pois reúne educação e entretenimento.

Para os alunos maiores, dá-se ênfase aos softwares que se ajustam ao que está sendo trabalhado em cada disciplina, por exemplo, "eu tenho um $C D$ do corpo humano [...] estudei e agora vou dizer para os alunos o que eu quero que vejam ali, o que eles podem pesquisar nesse $C D$, para isso têm que olhar o conteúdo, e os professores em geral, dificilmente, têm esse material" (professora, escola "6"). Ela retrata, dessa forma, as dificuldades encontradas pelos professores para desenvolver esse trabalho com os alunos maiores, pois é o momento em que cada professor precisará saber o que e como fazer para desenvolver as aulas no laboratório.

Diante disso, conforme a professora Betina, da escola "3" "vamos fazer uma oficina para os professores trabalharem a construção de softwares"; mas segundo a professora Lurdes, da escola "6", "gostaríamos de desenvolver software educacional, mas

\footnotetext{
${ }^{18}$ Como é o caso do Coelho Sabido, Passa-tempo da Mônica, Emília e a reforma da natureza, etc
}

vemos o grupo meio desmotivado para se envolver com essas atividades", pois em muitos momentos, notamos que para os professores desenvolverem esse tipo de material lhes é exigido um enorme tempo que geralmente não possuem ${ }^{19}-\mathrm{e}$, ao utilizarem esses materiais em sala de aula, em poucos minutos os alunos exploram o que foi desenvolvido em horas de trabalho. Então, apesar desses softwares educacionais serem criados, de acordo com os objetivos de cada turma - que é interessante para a educação, pois permite a criação de materiais de acordo com a necessidade dos alunos -, essa modalidade, pelo menos por enquanto, não encontrou uma situação adequada que permitisse sua produção.

Nesse sentido, alguns professores responsáveis pelo laboratório de informática procuram softwares direcionados para as disciplinas. Algumas escolas chegam a organizar uma espécie de banco de softwares, que tem a intenção de oferecer ao professor um acesso rápido a esses programas, basta apenas que o professor escolha e avalie cada software disponibilizado.

A utilização de computadores na educação exige uma intensificação do envolvimento dos professores e, para isso, necessita-se de tempo, que é escasso. Algumas atividades que envolvem a utilização desse cenário são muito requisitadas pelos alunos. Com isso, "quando um professor vai trazer uma turma da Educação Infantil ou Séries Iniciais, pergunto: 'o que vamos fazer?' a resposta quase sempre é jogada para mim, assim: 'vê tu'. Então disponibilizo esses joguinhos que possuímos" (Lurdes, escola " 6 "), ou seja, esses softwares servem como uma forma de entreter os alunos nesse espaço ${ }^{20}$. Mas, conforme a mesma professora, "são pré-selecionados pelos professores e são educacionais", ou seja, as fronteiras dos softwares educacionais são confundidas com a dos jogos, pois muitos softwares educacionais se assemelham a jogos eletrônicos. O problema não é confundir o jogo com software educacional, mas o contrário, pois, assim, estabelece-se o treinamento como forma de utilizar a informática na educação.

\footnotetext{
${ }^{19}$ Verificar o artigo "Domínio e Cultura informática na escola”, publicado na Revista Linhas v. 14, n. 27 (2013), Tópico 5.4 - "O domínio é responsável pelo aumento de trabalho dos docentes, mesmo quando promete sua redução".

${ }^{20}$ Idem nota anterior, Tópico 5.2 - "O discurso do domínio induz uma associação entre educação e entretenimento, ao invés da ludicidade”.
} 
Sem contar que os softwares educacionais, por serem fechados ${ }^{21}$, fazem com que o professor adapte suas aulas ao conteúdo neles propostos.

Segundo a professora Lurdes, entretanto, quando conseguem planejar o que será desenvolvido no laboratório, "utilizamos um editor de texto, fazemos desenhos e a Internet é o melhor lugar para fazer os trabalhos especificos de cada disciplina", talvez justificando a imensa utilização desse recurso, que será descrito no próximo tópico.

\subsection{A Internet}

Esse cenário é um dos mais utilizados na escola. Apesar de oferecer diversos tipos de serviços ${ }^{22}$, daremos maior ênfase para aqueles que as escolas entrevistadas salientam utilizar no seu dia-a-dia, que são os sites de busca ou procura de informações. Outros serviços encontrados na Internet também são vislumbrados pela escola, mas a professora Lurdes, da escola "6", destacou que a professora Juliana "desenvolveu um trabalho usando o correio eletrônico, uma única vez". Então, verificamos pouca utilização desses recursos nas escolas entrevistadas, o que não permitiu uma reflexão mais detalhada, embora se acredita ser relevante para a educação.

Da mesma forma, acontece com outros serviços. No desenvolvimento de atividades de criação de sites, conforme o depoimento da professora Mirian, "atualmente estamos desenvolvendo uma capacitação. Estamos aprendendo a construir páginas e blogs" (escola "7"). Isso mostra que há um interesse dos professores em efetuar essa produção. Talvez, posteriormente a este estudo, possamos encontrar mais subsídios para uma análise mais apurada ${ }^{23}$.

Mesmo que a Internet seja uma realidade da maioria das escolas, as que possuem fazem desse recurso uma forma para utilizar as TIC na educação. Quando não possuem Internet, as atividades no laboratório de informática são dificultadas. De acordo com a professora Mirian, "está difícil de os

\footnotetext{
${ }^{21}$ Geralmente, esses softwares são produzidos em grande escala para serem distribuídos pelo mundo inteiro, então seguem padrões pré-estabelecidos.

${ }^{22}$ Fóruns, listas de discussão, bate-papo, correio eletrônico, construção e disponibilização de sites e blogs, que são ferramentas poderosas e que auxiliam na produção do conhecimento.

${ }^{23}$ Uma análise de como esses recursos são aplicados na educação, em escolas da Europa, consultar: LAJUS\&MAGNIER. A escola na Era da Internet: os desafios do multimédia na educação. Lisboa: Instituto Piaget, 1998.
}

professores virem para o laboratório, porque não tem Internet". A professora ainda ressalta que as "disciplinas utilizam a Internet para pesquisa", o que provoca uma grande demanda pela utilização da rede, com a justificativa de realizar pesquisa. A Internet passa a ser quase sinônimo de pesquisar. Talvez, justifica-se a confusão criada entre pesquisa e busca de informações, pois "nossos alunos fazem muita cópia na Internet, copiam e colam no Word [...] não produzem nada, muitas vezes, eles não se dão o trabalho, nem de ler o que entregam para o professor" (Lurdes, escola "6"). O depoimento da professora ilustra uma preocupação com a cópia existente em diversas escolas.

Além disso, segundo a professora Lurdes, "os alunos entram em sites indevidos, nós ficamos de olho, mas eles são rápidos, quando chegamos perto, minimizam e maximizam a pesquisa" (escola " 6 "), o que obriga os professores a passarem "o tempo todo observando o que acessam" (idem) e, nesse caso, "peço a interferência do professor e a gente também interfere, porque tem regras no laboratório" (ibidem). Esses acontecimentos obrigam o professor a vigiar, ao invés de proporcionar novas discussões em sala de aula. Na medida em que se verifica que esse é um problema que costuma acontecer seguidamente, é possível utilizar programas para bloquear o acesso a sites impróprios.

Então, esses sites não devem ser o empecilho para impedir o acesso à Internet e, de fato, não são, pois quando a escola adquire um laboratório de informática, imediatamente mobiliza-se para efetuar a conexão. Conforme a professora Mirian, da escola "7", " a escola sem Internet é muito complicado". De acordo com a mesma professora, "com a Internet, como tínhamos anteriormente, era mais fácil [...], os alunos procuravam, viam que tinha mais assuntos, diversificava bastante o trabalho, estavam lendo, vendo e assim parece que fica muito pobre". Com isso, primeiro demonstra-se a dificuldade de algumas escolas em manter a Internet em funcionamento; depois, a enorme utilização dos serviços de busca, que propiciam o acesso a todo o tipo de informação.

Ao determinarmos que utilizaremos, por exemplo, a Internet para uma pesquisa durante nossas aulas, esquecemos que "alguns alunos gostam tanto de informática que poderiam ficar 3 ou 4 horas seguidas dentro do laboratório, 
enquanto para outros é uma tortura" (BONILLA, 1998, p. 42). Então, propor atividades em que todos devam utilizar computadores pode gerar conflitos desnecessários, como indisposição de alunos que odeiam o computador ou com aqueles que passam a aula entrando em sites de entretenimento, conforme afirma a professora Mara, da escola "4", "a gurizada ainda não se apoderou desse lugar como fonte de conhecimento, para eles isso aqui é diversão". O depoimento da professora ressalta a importância de os alunos começarem a ver o computador mais como uma máquina de ensinar ou onde se pode buscar o conhecimento.

Dessa forma, esquece-se que as TIC podem ser uma forma de possibilitar maior participação dos alunos na produção do conhecimento, pois amplia as fronteiras de acesso às informações e, ainda, condiciona uma extrapolação destas. De forma que, ao desenvolvermos um projeto com as TIC, a criança desejará brincar com a fronteira e irá, justamente, onde a colocamos. Conforme relata uma professora da escola "3": "nossos alunos da 4" série estavam fazendo um trabalho sobre tuberculose e outras doenças, veio um deles e trouxe várias informações sobre doenças sexualmente transmissíveis, isso é complicado para o professor [...] é preocupante, porque não é o momento de todos os alunos, é de um só e aí é que mora o perigo".

É explícita, nesse caso, a preocupação da professora em relação à criança trazer informações que estão fora de seu planejamento. No entanto, eis uma das principais mudanças que o ciberespaço proporciona: a possibilidade de os alunos também trazerem informações para serem discutidas na escola. A criança traz essas informações porque está brincando com a fronteira. De alguma maneira, ela percebe que essa torção feita no projeto é arriscada, é perigosa ou é incômoda.

É preciso, ainda, dizer que o estabelecimento de fronteiras é necessário ${ }^{24}$, pois a escola sem estas é qualquer coisa, menos escola. E, faz parte de nossa função enquanto educadores transmitir valores, tradições e também educar por aquilo que nós somos. No entanto, a criança quer sair e ver o que existe do outro lado da fronteira, é um impulso natural do ser

\footnotetext{
${ }^{24}$ A escola sabe estabelecer as regras, como, por exemplo, proibindo o acesso
} a sites impróprios. humano. A Internet, de certa maneira é a possibilidade técnica e concreta de proporcionar isso, é uma porta de saída e entrada. O aluno sai, mas volta e o professor faz a escuta e estimula a fala: “- Quer me mostrar? - Ah! Doença sexualmente transmissível". O professor pode fazer uma aula disso.

Caso a aula, entretanto, for fechada, não permitirá que ocorra essa comunicação, independente de usarmos as TIC ou não, pois, na grande maioria dos casos, criamos fronteiras rígidas e, muitas vezes, intransponíveis, conforme relata a professora Juliana, da escola "6": "se os alunos vão pesquisar na Internet, eu gosto antes de estar fazendo uma busca. Daí o aluno vem e eu já tenho alguns sites vistos". Desse modo, restringe o acesso a qualquer outro tipo de informação e demonstra a preocupação que possuímos em ver nossos alunos diante de um espaço de acesso à informação aberto e não termos o controle. De acordo com Serres (2000) essa é uma antiga preocupação, pois com as bibliotecas também acontecia. A forma de controle descrita anteriormente pela professora assemelha-se ao controle estabelecido nas famílias mais tradicionais, em que não se permitiam às mulheres acesso a leitura e aos estudos.

Com essa mesma preocupação, propomos pesquisas na Internet, enciclopédias virtuais e outros, tudo em tempos que costumamos delimitar. Definimos como e quando desenvolver a utilização de computadores. Com isso podamos o que a informática poderia proporcionar de mais maravilhoso, a capacidade de inovação e criação da comunidade escolar, pois nosso medo e insegurança frente à curiosidade dos alunos faz com que sejamos precavidos em relação ao novo, conforme ressalta uma professora da "escola 3": "É que sempre vai ter que ter uma orientação, porque muitas vezes já tivemos problemas, têm alunos que vão com um interesse para o laboratório de informática e outros vão com outros interesses, e não são poucas as vezes, que eles entram em páginas indevidas, tu tens que ver. Então, sempre tem que ter uma orientação do que poderia ser usado".

No entanto, confunde-se orientação apenas com disciplinamento. Dessa forma, esquece-se que a escola é o lugar de excelência do conhecimento e, justamente por isso, precisamos aprender a utilizar esse veículo de informação tão versátil. Não se trata apenas de se apropriar de conhecimentos técnicos, 
que permitam um livre trânsito no ciberespaço, mas de construção ética, que nos auxilie na reflexão sobre a utilização das TIC.

Caso contrário, em uma situação em que todos os alunos disponham de um computador móvel de pequeno porte ${ }^{25}$, com acesso a Internet sem fio, ou seja, podemos acessar todo o tipo de informação, sem nenhuma restrição. Como esses espaços serão organizados? Como os alunos se apropriarão desses recursos? Entendemos que são questões que precisamos pensar, pois "ensinar exige [...] a disponibilidade ao risco, a aceitação do novo que não pode ser negado ou acolhido só porque é novo" (FREIRE, 1996, p.39). Mas, exige-se uma predisposição para avaliá-lo criticamente, bem como, as ações que a partir dele são produzidas. Levando em conta que,

A resposta às incertezas da ação é constituída pela escolha refletida de uma decisão, a consciência da aposta, a elaboração de uma estratégia que leve em conta as complexidades inerentes às próprias finalidades, que possa se modificar durante a ação em função dos imprevistos, informações, mudanças de contexto e que possa considerar o eventual torpedeamento da ação, que teria tomado uma direção nociva. (MORIN, 2001, p.91).

Assim, estaríamos fazendo nosso papel de educadores, trazendo o novo e orientando os alunos sobre possíveis usos e abusos. Não significaria que estaríamos afastando os alunos dos perigos do ciberespaço, somente através da imposição de regras, impedindo-os de compreender o que lhes serve ou não. As regras são necessárias, mas, ao invés de somente restringir o acesso, precisa-se também discutir e conscientizar nossos alunos e filhos, de forma que possamos ajudá-los a discernir o que é pernicioso para suas vidas do que é importante para a formação de um cidadão mais humano.

\section{Considerações finais}

Entender a presença da cultura informática e a ilustração de seus entrelaçamentos e enfrentamentos com a presença das TIC na escola, a partir da fala

\footnotetext{
${ }^{25}$ Como pode ser observado em algumas escolas que receberam o projeto Um Computador por Aluno (UCA). Trata-se de uma parceria do governo federal com municípios para aquisição de um computador por aluno. Das escolas entrevistadas nenhuma possuía esse projeto implantado, mas todas demonstram enorme interesse em participar, conforme conversas informais com as equipes diretivas.
}

dos professores, reforçam que as TIC, pelo menos por enquanto, agravam ainda mais o problema que há muito tempo aflige a escola, a educação bancária (FREIRE, 1987). Esquece-se que vivemos na sociedade intensiva do conhecimento (DEMO, 2004) e que acesso às informações não é mais o problema. Pelo contrário, o excesso passa a sê-lo. Então, se disseminarmos o discurso do domínio, promovemos apenas uma aceleração do trânsito de informações. A velocidade proporcionada pela informática é utilizada através do domínio para, literalmente, transformarmos os alunos em depósito de dados, ou seja, a velocidade acaba atrapalhando, ao invés de contribuir à produção do conhecimento.

Como se percebeu nas falas dos professores, o discurso do domínio é responsável por definir o que podemos e o que devemos fazer com as TIC, pois se apresentam como um método salvador para a educação. O que acarreta o desenvolvimento das mesmas formas de uso em diferentes lugares. Independe da certeza que cada educador leva consigo, de que cada escola tem sua caminhada. Aqui foi demonstrado que o domínio leva as comunidades escolares a optarem por modelos de utilização das TIC que deixam de lado as características de cada instituição. Por isso, precisamos aprender a caminhar com nossas pernas para criar nossos próprios percursos.

Também, com esse discurso, readaptamos o novo para se encaixar às velhas metodologias e acabamos fazendo com que recursos potenciais transformem-se em meros quadros eletrônicos, perpetuando ainda mais um modelo de educação que não leva em conta o que cada aluno traz para a escola. Utilizam-se novas formas de acesso a informação, mais divertida, mais atrativa. Esquece-se que o conhecimento é esforço, é concentração, é disciplina, é estudo sério e compenetrado. Além disso, através do domínio se define rigidamente as fronteiras no ciberespaço e até mesmo que atividades serão desenvolvidas na escola, eliminando a interdisciplinaridade existente na hipertextualidade ${ }^{26}$.

Por essa via, impulsiona-se uma massificação do uso de computadores e se implementa uma política de uso das TIC que potencializa apenas o consumo

\footnotetext{
${ }^{26}$ Verificar o artigo "Domínio e Cultura informática na escola”, publicado na Revista Linhas v. 14, n. 27 (2013).Tópico 5.6 - "O domínio estabelece formas de controle que domesticam a interdisciplinaridade existente na hipertextualidade".
} 
de produtos eletrônicos e, consequentemente, a formação de potenciais consumidores.

Acabamos por entrar em um círculo vicioso de atualizações tecnológicas que a escola dificilmente consegue acompanhar. Podendo, a partir disso, até mesmo perder a sua essência perante sua comunidade que é de ser um lugar de excelência para a formação de futuros cidadãos que participem da produção do conhecimento, pois a busca pelo domínio empurra os indivíduos para dentro do núcleo do furacão do consumo tecnológico.

Ao limitarmos às TIC a isso, esquecemos que a informática é cultura e como tal implica em novas formas de ser, conhecer e se relacionar. Conforme Nize Pellanda (2005, p. 67) "nós não teremos limites para o nosso desenvolvimento humano se fizermos da técnica um instrumento de apropriação de nós mesmos e de nossa cultura". Assim, a partir da possibilidade de ir criando uma cultura informática de forma mais livre e criativa, outro contexto se estrutura, pois não é novidade que na maioria das vezes as pessoas se apropriam das TIC de uma forma lúdica. Amplia-se, então, a rede de usos e significados. As pessoas, ao estabelecerem um ciclo de trocas com a intenção de renovar e circular seus saberes, apropriam-se de um conhecimento que dificilmente é socializado para a maioria das pessoas.

Nesse sentido, a escola tem papel fundamental, uma vez que é o lugar onde as sementes são plantadas e germinadas. Então, nada mais justo do que semear a produção do conhecimento de forma cooperativa. Para isso, precisamos entender a informática não como algo pré-determinado que basta seguir fórmulas e garantir seu uso diário. Se desejarmos a efetiva união da informática com a educação, necessitamos entender que esse é um problema complexo e multifacetado, que não depende apenas de conhecimentos técnicos de profissionais de informática e/ou pedagogos e sim de educadores com um profundo conhecimento tecnológico ${ }^{27}$. Não se trata de propor alternativas e/ou soluções possíveis para efetuar o uso de computadores, mas, permitir que o coletivo da escola pense em seus próprios caminhos com o objetivo de ampliar os horizontes cognitivos dos sujeitos.

\footnotetext{
${ }^{27}$ Como é o caso dos profissionais formados nos Cursos de Licenciatura em Computação.
}

\section{Referências Bibliográficas}

BONILLA, Maria Helena Silveira (org). I Seminário de Educação e Informática: relatório das ações desenvolvidas durante o evento. Ijuí: Ed. UNIJUÍ, 1998. (Coleção trabalhos acadêmicos-científicos. Série eventos acadêmicos).

CASEMENT, Charles; ARMSTRONG, Alison. A criança e a máquina: como os computadores colocam a educação de nossos filhos em risco. Traduzido por: Ronaldo Cataldo Costa. Porto Alegre: Artmed Editora, 2001

CAMBRAIA, Adão Caron. Domínio e cultura informática na escola. Revista Linhas. (UDESC - Florianópolis. Online), v. 14, p. 105-133, Jul/Dez. 2013.

DELEUZE, Gilles. Post-scriptum sobre as sociedades de controle. In: Conversações. Traduzido por: Peter Pál Pelbart. 1.ed. 1992.

DEMO, Pedro. Professor do futuro e reconstrução do conhecimento. Petrópolis, RJ: Vozes, 2004.

FOUCAULT, Michel. Vigiar e Punir: nascimento da prisão. 27. ed. Traduzido por: Raquel Ramalhete. Petrópolis: Vozes, 2003.

FREIRE, Paulo. Pedagogia da Autonomia: saberes necessários à prática educativa. 18. ed. São Paulo: Editora Paz e Terra, 1996.

FREIRE, Paulo. Pedagogia do oprimido. 17. Ed. Rio de Janeiro: Paz e Terra, 1987.

GUATTARI, Félix. Caosmose: um novo paradigma estético. Traduzido por: Ana Lucia de Oliveira e Lúcia Claudia Leão. São Paulo: Ed. 34, 1992. (Coleção TRANS).

MACHADO, Nílson José. Educação: projetos e valores. São Paulo: Escrituras Editora, 2000.

Matemática e educação: alegorias, tecnologias e temas afins. 4.ed. São Paulo: Cortez, 2002.

MINAYO, Maria C. de S. Pesquisa social: teoria, método e criatividade. Petrópolis: Vozes, 1996.

MORAES, Roque; GALIAZZI, Maria do Carmo. Análise Textual Discursiva. 2. Ed. Ijuí: Ed. UNIJUÍ, 2013.

MORIN, Edgar. Os sete saberes necessários à educação do futuro. Traduzido por: Catarina Silva e Jeanne Sawaya. 3. ed. São Paulo: Cortez, 2001.

PELLANDA, Nize. Pierre Lévy e Humberto Maturana: convergências paradigmáticas. In: PELLANDA, Nize Maria Campos; PELlANDA, Eduardo Campos (Org.). Ciberespaço: um hipertexto com Pierre Lévy. Porto Alegre: Artes e Ofícios, 2000.

SERRES, Michel. Novas Tecnologias e Sociedade Pedagógica: uma conversa com Michel Serres. 
Entrevistadores: Rogério da Costa e Ricardo R. Teixeira. Acessado em: www.interface.org.br/revista6/entrevista1. pdf. publicada em Fevereiro de 2000.

TURKLE, Sherry. A Vida no Ecrã: a identidade na era da internet. Lisboa: Relógio d'água, 1997. (Coleção Sociedade Digital).

UNESCO. O Perfil dos professores brasileiros: o que fazem, o que pensam, o que almejam. São Paulo: Moderna, 2004.

Recebido em: 19-12-2014

Aceito em: 17-02-2015 